\title{
Rapid and Efficient Detection of 16SrI Group Areca Palm Yellow Leaf Phytoplasma in China by Loop-Mediated Isothermal Amplification
}

\author{
Shao-shuai Yu ${ }^{1}$, Hai-yan Che ${ }^{2}$, Sheng-jie Wang ${ }^{3}$, Cai-li Lin ${ }^{4}$, Ming-xing Lin ${ }^{1}$, Wei-wei Song ${ }^{1}$, Qing-hua Tang ${ }^{1}$, \\ Wei Yan', and Wei-quan Qin (iD ${ }^{1 *}$ \\ ${ }^{1}$ Coconut Research Institute of Chinese Academy of Tropical Agricultural Sciences, Wenchang 571339, China \\ ${ }^{2}$ Environment and Plant Protection Institute, Chinese Academy of Tropical Agricultural Sciences, Haikou 571101, China \\ ${ }^{3}$ Research Institute of Tropical Forestry, Chinese Academy of Forestry, Guangzhou 510520, China \\ ${ }^{4}$ Research Institute of Forest Ecology, Environment and Protection, Chinese Academy of Forestry, Beijing 100091, China
}

(Received on June 4, 2020; Revised on August 3, 2020; Accepted on August 20, 2020)

Areca palm yellow leaf (AYL) disease caused by the 16SrI group phytoplasma is a serious threat to the development of the Areca palm industry in China. The 16S rRNA gene sequence was utilized to establish a rapid and efficient detection system efficient for the 16SrI-B subgroup AYL phytoplasma in China by loopmediated isothermal amplification (LAMP). The results showed that two sets of LAMP detection primers, 16SrDNA-2 and 16SrDNA-3, were efficient for 16SrIB subgroup AYL phytoplasma in China, with positive results appearing under reaction conditions of $64^{\circ} \mathrm{C}$ for $40 \mathrm{~min}$. The lowest detection limit for the two LAMP detection assays was the same at $200 \mathrm{ag} / \mu \mathrm{l}$, namely approximately 53 copies/ $\mu$ l of the target fragments. Phytoplasma was detected in all AYL disease samples from Baoting, Tunchang, and Wanning counties in Hainan province using the two sets of LAMP primers 16SrDNA-2 and 16SrDNA-3, whereas no phytoplasma was detected in the negative control. The LAMP method established in this study with comparatively high sensitivity and stability, provides reliable results that could be visually detected, making it suitable for application and

\footnotetext{
*Corresponding author.

Phone) +86-898-63331269, FAX) +86-898-63330673

E-mail) qwq268@163.com

ORCID

Wei-quan Qin

https://orcid.org/0000-0002-3460-3526

(c) This is an Open Access article distributed under the terms of the Creative Commons Attribution Non-Commercial License (http:// creativecommons.org/licenses/by-nc/4.0) which permits unrestricted noncommercial use, distribution, and reproduction in any medium, provided the original work is properly cited.
}

Articles can be freely viewed online at www.ppjonline.org. research in rapid diagnosis of AYL disease, detection of seedlings with the pathogen and breeding of diseaseresistant Areca palm varieties.

Keywords : Areca palm yellow leaf disease, loop-mediated isothermal amplification, phytoplasma, rapid detection, $16 \mathrm{~S}$ rRNA gene sequence

Handling Editor : Sang-Wook Han

Phytoplasma is a prokaryotic pathogen that parasitizes the phloem of plants, has no cell wall, and can not be isolated and cultured in vitro (Doi et al., 1967). Areca palm is a common tropical evergreen palm and an important resource used as traditional Chinese medicine in China. Areca palm yellow leaf (AYL) disease, caused by phytoplasma, is a devastating disease affecting Areca palm production; this disease has been reported in India, Sri Lanka, and Hainan province of China (Che et al., 2010; Ramaswamy et al., 2013; Silva et al., 2015). Based on 16S rRNA and $\sec A$ sequence analysis, Ramaswamy et al. (2013) found that the AYL phytoplasma from the Sulia area of India belonged to the 16SrXI group. Muddumadiah et al. (2014) showed that the AYL phytoplasma from the Sulia area belonged to the 16SrI group based on the 16S rRNA gene sequence analysis. Silva et al. (2015) found that AYL disease in Sri Lanka was caused by the $16 \mathrm{SrXIV}$ group by performing $16 \mathrm{~S}$ rDNA and secA cloning and sequencing. PCR amplification of the 16S rRNA gene indicated that AYL disease in China is caused by $16 \mathrm{SrI}-\mathrm{G}$ and $16 \mathrm{SrI}-\mathrm{B}$ subgroup phytoplasma (Che et al., 2010; Zhou et al., 2010). The titer of AYL phytoplasma is relatively low in diseased Areca palm tissues; thus, detection of such diseases depends on nested 
PCR or real-time fluorescent PCR (Che and Luo, 2011; Nair et al., 2014). However, these methods are time-consuming, complex operation, and easy contamination. Thus, the applicability of these diagnostic methods is limited.

Loop-mediated isothermal amplification (LAMP) is a constant temperature nucleic acid amplification method developed by Notomi et al. (2000). This method is efficient, simple to perform, does not require complex instruments, and has a short detection cycle and easily visualized results. It is suitable for basic level research and disease diagnosis in the field. Based on the housekeeping gene groEL, Sugawara et al. (2012) developed LAMP primers for detecting phytoplasma strains within the Candidatus Phytoplasma asteris group, including onion yellows (OY). Based on the 16S rRNA gene of 16SrXI group AYL phytoplasma in India, Nair et al. (2016) established a LAMP detection system. Wang et al. (2017) developed LAMP primers suitable for detecting phytoplasma strains in China such as paulownia witches'-broom phytoplasma based on the tuf gene sequence. However, variations are observed in different $16 \mathrm{Sr}$ groups or subgroups, plant hosts, and phytoplasma housekeeping genes such as 16S rRNA, tuf, and groEL. Therefore, LAMP detection systems established based on different levels of variation and target genes show large differences in sensitivity for detecting various 16Sr phytoplasma groups or subgroups in their respective plant hosts.

AYL disease, caused by 16 SrI-B subgroup phytoplasma, is a serious agricultural issue in Hainan province of China. Pathogen detection mainly depends on nested PCR or realtime fluorescent PCR. Therefore, we developed a LAMP detection system efficient for 16SrI group AYL phytoplasma based on the 16SrRNA gene sequence of the phytoplasma. This rapid, efficient, and simple approach is suitable for rapid detection and field diagnosis of the disease and may be applied to Areca palm breeding and seedling quarantine.

\section{Materials and Methods}

Materials. Diseased Areca palm samples were collected from Baoting, Tunchang, and Wanning counties in Hainan province in China in July 2019, with a total of six. Healthy Areca palm samples were obtained from Wanning county of Hainan province in China in July 2019, with a total of six.

DNA extraction and PCR amplification. Fresh Areca palm leaves $(0.10 \mathrm{~g})$ were weighed and ground with a highspeed tissue grinder (Servicebio Co., Ltd, Wuhan, China). Using the CTAB DNA extraction method, total palm DNA was extracted according to the instructions of the rapid extraction kit for plant genomic DNA (CTAB Plant Genome DNA Rapid Extraction Kit, Aidlab Biotechnologies Co., Ltd, Beijing, China); the DNA samples were stored at $-20^{\circ} \mathrm{C}$ until use. Extracted palm DNA was amplified by direct PCR using primer pair P1/P7 (Deng and Hiruki, 1991; Schneider et al., 1995) and nested PCR using primer pair R16mF2/R16mR1 (Lee et al., 1993). The 25- $\mu$ amplification system contained $20 \mathrm{ng}$ DNA template, 0.5 $\mu 1 \mathrm{P} 1 / \mathrm{P} 7(10 \mu \mathrm{M}), 2 \times$ PCR premix $(0.05 \mathrm{U} / \mu 1 \mathrm{Taq}$ DNA polymerase, $4 \mathrm{mmol} / 1 \mathrm{MgCl}_{2}$, and $0.4 \mathrm{mmol} / 1 \mathrm{dNTPs}$ ) with $12.5 \mu \mathrm{l}$, and add $\mathrm{ddH}_{2} \mathrm{O}$ up to $25 \mu \mathrm{l}$. The reaction conditions were as follows: $94^{\circ} \mathrm{C}$ for $5 \mathrm{~min} ; 94^{\circ} \mathrm{C}$ for $45 \mathrm{~s}, 52^{\circ} \mathrm{C}$ for $2 \mathrm{~min}$, and $72^{\circ} \mathrm{C}$ for $1 \mathrm{~min}$ for 35 cycles in total; $72^{\circ} \mathrm{C}$ for $10 \mathrm{~min}$ final extension. The primary (P1/P7) PCR products were diluted 50-fold as the template DNA for nested PCR. Nested PCR reaction containing $1 \mu$ diluted template DNA, R16mF2/R16mR1 $0.5 \mu \mathrm{l}(10 \mu \mathrm{M}), 2 \times$ PCR premix ( $0.05 \mathrm{U} / \mu \mathrm{l} \mathrm{Taq}$ DNA polymerase, $4 \mathrm{mmol} / 1 \mathrm{MgCl}_{2}$, and 0.4 $\mathrm{mmol} / \mathrm{l} \mathrm{dNTPs}$ ) with $12.5 \mu \mathrm{l}$, and add $\mathrm{ddH}_{2} \mathrm{O}$ up to $25 \mu \mathrm{l}$ was performed as follows: $94^{\circ} \mathrm{C}$ for $5 \mathrm{~min}, 94^{\circ} \mathrm{C}$ for $45 \mathrm{~s}$, $52^{\circ} \mathrm{C}$ for $1 \mathrm{~min}$ for $30 \mathrm{~s}$, and $72^{\circ} \mathrm{C}$ for $1 \mathrm{~min}$ for 35 cycles, a final extension at $72^{\circ} \mathrm{C}$ for $10 \mathrm{~min}$ final extension. The PCR products were visually detected by $1.5 \%$ agarose gel electrophoresis through ethidium bromide staining.

LAMP primer design and synthesis. Based on the $16 \mathrm{SrI}$ group phytoplasma 16S rRNA gene sequence (kp662119) published in NCBI (Yu et al., 2017), primer Explorer V4 (http://primexplorer.jp/e/) was used to design the LAMP primers. Multiple sets of LAMP primers were designed based on the conserved sequence of the 16S rRNA gene, from which LAMP primers efficient for 16SrI group AYL phytoplasma were selected. The primers of the LAMP included forward outer primer $\mathrm{F} 3$, reverse outer primer $\mathrm{B} 3$, forward inner primer FIP (FIC + F2), and reverse inner primer BIP $(\mathrm{BIC}+\mathrm{B} 2)$. Primers were synthesized by Biotechnology (Shanghai) Co., Ltd. (Shanghai, China) following purity evaluation by high-performance liquid chromatography, as shown in Table 1.

Establishment of LAMP detection system. According to the constant temperature amplification kit from Eiken China Co., Ltd. (Shanghai, China), the LAMP amplification system for AYL phytoplasma was established. The samples of AYL disease and healthy Areca palm from Wanning of Hainan province in China were used as experimental materials. The amplification reaction was a total volume of $25.0 \mu \mathrm{l}$ which contained $12.5 \mu \mathrm{l} 2 \times$ reaction buffer, $1.0 \mu \mathrm{l}$ BST DNA polymerase, primers $(40 \mathrm{pmol} / \mu \mathrm{l} \mathrm{FIP/}$ 
Table 1. Primer sequences used in the LAMP and PCR amplification

\begin{tabular}{ll}
\hline Primer name & Primer sequence $\left(5^{\prime}\right.$ end-3' end $)$ \\
\hline 16SrDNA-F3-2 & GCATGGTTGTCGTCAGCT \\
16SrDNA-B3-2 & GCCAAAAACTTGCGCTTCA \\
16SrDNA-FIP-2 & GGCAGTCTTGCTAAAGTCCCCACGATGTTGGGTTAAGTCCCGC \\
16SrDNA-BIP-2 & ACGACGTCAAATCATCATGCCCCGCTACCCTTTGTAACAGCCAT \\
16SrDNA-LF-2 & AATAAGGGTTGCGCTCGTT \\
16SrDNA-LB-2 & ATGACCTGGGCTACAAACGT \\
16SrDNA-F3-3 & GCTGAAGCGCAAGTTTTTGG \\
16SrDNA-B3-3 & ACCTTAGACGGTTCCCTCTTC \\
16SrDNA-FIP-3 & GCGACATGCTGATTCGCGATTACTCAGTTCGGATTGAAGTCTGC \\
16SrDNA-BIP-3 & ACGTTCTCGGGGTTTGTACACACTTGCGAAGTTAGGCCACC \\
16SrDNA-LF-3 & TCCAACTTCATGAAGTCGAGTT \\
16SrDNA-LB-3 & CGCCCGTCAAACCACGA \\
P1 & AAGAGTTTGATCCTGGCTCAGGATT \\
P7 & CGTCCTTCATCGGCTCTT \\
R16mF2 & CATGCAAGTCGAACGGA \\
R16mR1 & CTTAACCCCAATCATCGAC \\
\hline
\end{tabular}

LAMP, loop-mediated isothermal amplification.

$\mathrm{BIP}, 1 \mu \mathrm{l} 20 \mathrm{pmol} / \mu \mathrm{LF} / \mathrm{LB}, 5 \mathrm{pmol} / \mu \mathrm{l} \mathrm{F} / \mathrm{B} 3), 2 \mu \mathrm{fluo}-$ rescent visual detection reagent, $20 \mathrm{ng}$ DNA template, and deionized water up to $25 \mu \mathrm{l}$. The reaction was performed at $64^{\circ} \mathrm{C}$ for $70 \mathrm{~min}$ in a LA-320C real time turbidimeter (Eiken Chemical Co., Ltd.). The LAMP reaction results were observed after the reaction. A positive control $(\mathrm{P}+)$ and negative control ( $\mathrm{N}-$ ) from a LAMP kit (Eiken China Co., Ltd.) were used as experimental controls, and each experiment was repeated three times.

Evaluation of LAMP amplification products. The amplification results of the LAMP assay were evaluated by two methods. First, the amplification reaction tube was placed in a constant temperature fluorescence detector and the fluorescence signal was read in real-time. If the amplification curve was "S"-shaped, the result was determined to be positive, indicating that phytoplasma was present in the tested sample. If the amplification curve was not "S"-shaped, the sample was considered as negative with no phytoplasma in the tested sample. In the second method, fluorescent visual detection color reagent (calcein-manganese chloride solution) was added before the incubation reaction, and the result was evaluated according to the color change. An amplified product appearing as emerald green was considered as positive for the presence of phytoplasma. If the amplified product remained orange, the results were considered as negative and did not contain phytoplasma.

Sensitivity analysis of LAMP detection system. The sen- sitivity of the LAMP detection system was determined using a recombinant plasmid containing the 16S rRNA gene. 16SrDNA was inserted into the pUC57 plasmid and diluted to various concentrations for detection. The recombinant plasmid was synthesized by Biotechnology (Shanghai) Co., Ltd. After centrifugation of $4 \mu \mathrm{g}$ dry powder of $16 \mathrm{~S}$ rDNA recombinant plasmid, $200 \mu$ ldeionized water was added to a concentration of $20 \mathrm{ng} / \mu \mathrm{l}$. This sample was serially diluted by 10 -fold to $2 \mathrm{ng} / \mu \mathrm{l}, 200 \mathrm{pg} / \mu \mathrm{l}, 20 \mathrm{pg} / \mu \mathrm{l}, 2 \mathrm{pg} / \mu \mathrm{l}, 200$ $\mathrm{fg} / \mu \mathrm{l}, 20 \mathrm{fg} / \mu \mathrm{l}, 2 \mathrm{fg} / \mu \mathrm{l}, 200 \mathrm{ag} / \mu \mathrm{l}, 20 \mathrm{ag} / \mu \mathrm{l}$, and $2 \mathrm{ag} / \mu \mathrm{l} ; 2 \mu \mathrm{l}$ of sample were added to each tube. After the reaction, the sensitivity of the LAMP detection system was determined.

Stability of LAMP detection system. Using the established LAMP detection system, palm samples with AYL disease from Baoting, Tunchang, and Wanning counties in Hainan, China were evaluated. Total DNA was extracted from the samples, and LAMP amplification was carried out after PCR amplification verification. After the reaction, the results of the LAMP reaction were observed to verify the stability of the system.

Statistical analysis. The data in the study were analyzed by using Mean, Std. Deviation and One-Way ANOVA employing SPSS version 13.0 software (SPSS Inc., Chicago, IL, USA), with significant level $P=0.05$. The column figure was obtained employing SigmaPlot version 12.0 software. 


\section{Results}

Establishment of LAMP detection system. AYL phytoplasma samples and healthy samples from Wanning, Hainan province were used as positive $(\mathrm{WN}+)$ and negative (WN-) experimental materials, with deionized water (CK) as the control. We screened multiple sets of LAMP primer groups, which were designed based on the target $16 \mathrm{~S}$ rRNA gene sequence. Based on the reaction procedure described by the constant temperature amplification kit, a LAMP detection system for AYL phytoplasma was established. Two sets of LAMP primer groups based on the 16S rRNA gene designed for AYL phytoplasma, 16S rDNA2 LAMP primer group, and 16S rDNA-3 LAMP primer group, were screened. The two LAMP primer groups were amplified by constant temperature amplification at $64^{\circ} \mathrm{C}$ for $70 \mathrm{~min}$. "S"-shaped amplification curves were obtained for samples of AYL phytoplasma amplified by the two LAMP primer groups and the positive control $(\mathrm{P}+)$ of the LAMP kit, and the reaction solution turned to emerald green after

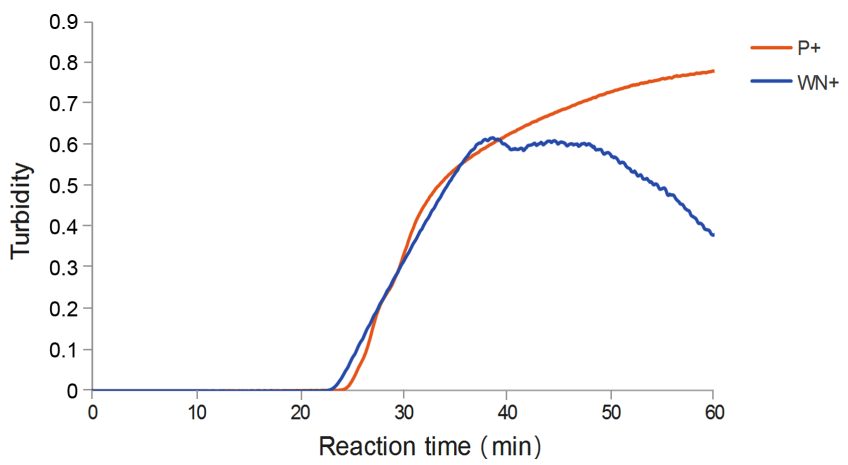

Fig. 1. Real-time amplification curve of 16SrDNA-2 loopmediated isothermal amplification (LAMP) primers of Areca palm yellow leaf (AYL) phytoplasma. $\mathrm{P}+$, positive control of the LAMP kit (Eiken China Co., Ltd.); WN+, AYL phytoplasma sample.

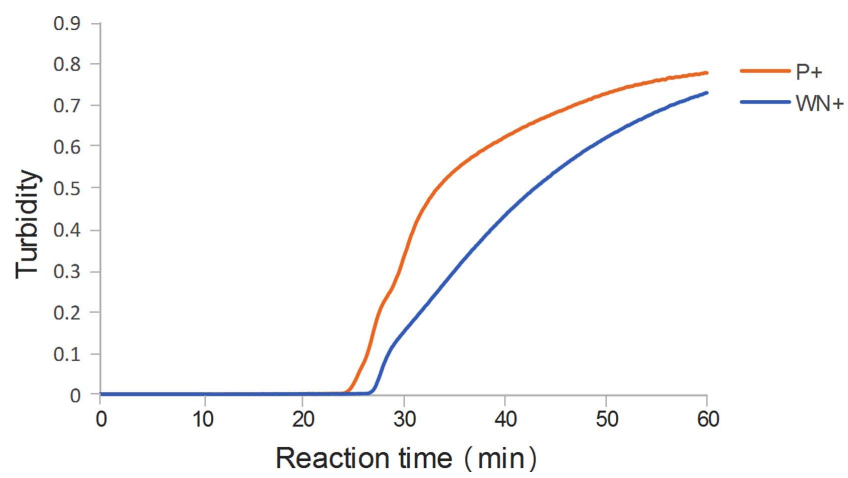

Fig. 2. Real-time amplification curve of 16SrDNA-3 loopmediated isothermal amplification (LAMP) primers of Areca palm yellow leaf (AYL) phytoplasma. $\mathrm{P}+$, positive control of the LAMP kit (Eiken China Co., Ltd.); WN+, AYL phytoplasma sample.

adding the chromogenic solution before the reaction. In contrast, "S"-shaped amplification curves and color change reactions were not observed in the healthy Areca palm samples, negative control (N-) of the LAMP kit, or deionized water control, as shown in Figs. 1-3. LAMP detection of AYL phytoplasma was completed within 40 min from adding the genomic DNA of AYL phytoplasma to obtaining the results, demonstrating the rapid detection of AYL phytoplasma.

Sensitivity of LAMP detection system. The 16S rDNA recombinant plasmid based on the pUC57 plasmid vector was diluted to $20 \mathrm{ng} / \mu \mathrm{l}$ using deionized water and this stock solution was used for 10-fold serial dilutions. The diluted solution was used as a template for LAMP detection, with results observed using the real-time amplification curve and color change reaction. The results showed that two LAMP primer groups, 16SrDNA-2 and 16SrDNA-3, produced an "S"-shaped real-time amplification curve and color change reaction at a template concentration of $200 \mathrm{ag} / \mu \mathrm{l}$, whereas there was no "S"-shaped real-time amplification curve or
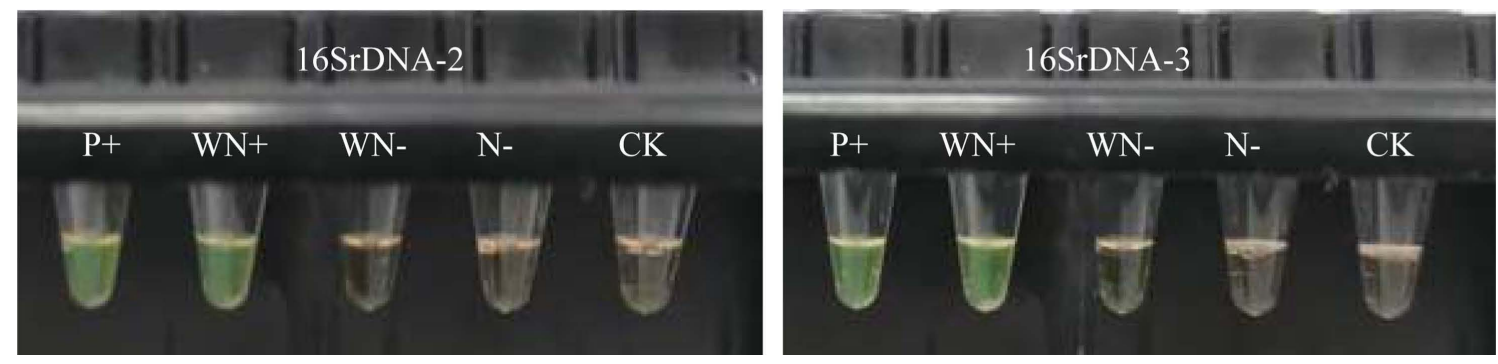

Fig. 3. Color change reactions of 16SrDNA-2 and 16SrDNA-3 loop-mediated isothermal amplification (LAMP) primers of Areca palm yellow leaf (AYL) phytoplasma. P+, positive control of the LAMP kit (Eiken China Co., Ltd.); N-, negative control of the LAMP kit (Eiken China Co., Ltd.); WN+, AYL phytoplasma sample; WN-, healthy Areca palm sample; CK, deionized water. 


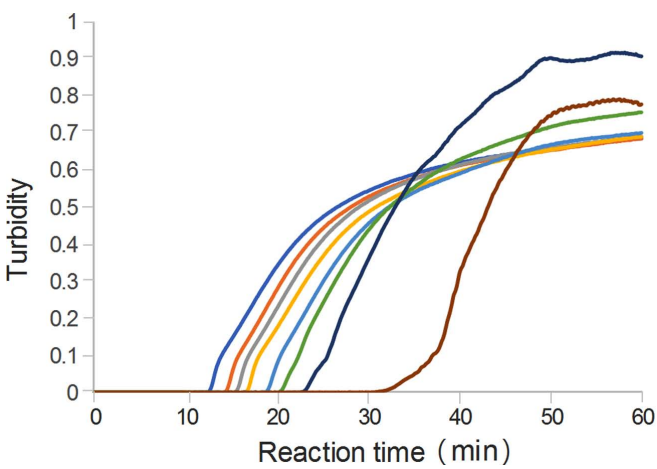

Fig. 4. Real-time amplification curve of 16SrDNA-2 loop-mediated isothermal amplification primers of Areca palm yellow leaf (AYL) phytoplasma.

color change reaction when the template concentration was $20 \mathrm{ag} / \mu \mathrm{l}$, as shown in Figs. 4-6. Thus, the two LAMP primer groups of 16SrDNA-2 and 16SrDNA-3 of AYL phytoplasma were efficient. The lowest detection limit of these primer groups was $200 \mathrm{ag} / \mu \mathrm{l}$, which corresponds to approximately 53 copies/ $\mu 116 \mathrm{~S}$ rRNA gene fragments calculated based on the Avogadro's constant. In addition, it could be seen that the detection time of different concentrations of templates is significantly different $(P<0.05)$ using 16SrDNA-2 or 16SrDNA-3 LAMP primer sets. For the same concentrations of templates, the detection time of 16SrDNA-2 primers is comparatively shorter than that of

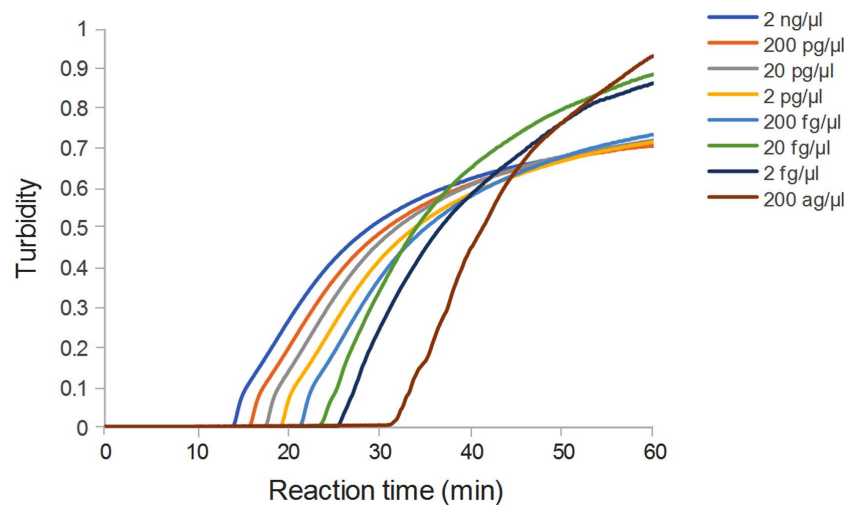

Fig. 5. Real-time amplification curve of 16SrDNA-3 loop-mediated isothermal amplification primers of Areca palm yellow leaf (AYL) phytoplasma.

16SrDNA-3 primers mostly with significant difference $(P$ $<0.05$ ) as shown in Fig. 7.

Stability and application of LAMP detection system. The established LAMP detection systems were used to detect AYL disease samples from Baoting, Tunchang, and Wanning counties in Hainan province, and the stability of the two LAMP detection systems was determined. The test samples were first evaluated by PCR amplification with the $\mathrm{P} 1 / \mathrm{P} 7$ and $\mathrm{R} 16 \mathrm{mF} 2 / \mathrm{R} 16 \mathrm{mR} 1$ primers. The target sequence band (1,400 bp) of AYL phytoplasma was detected in the
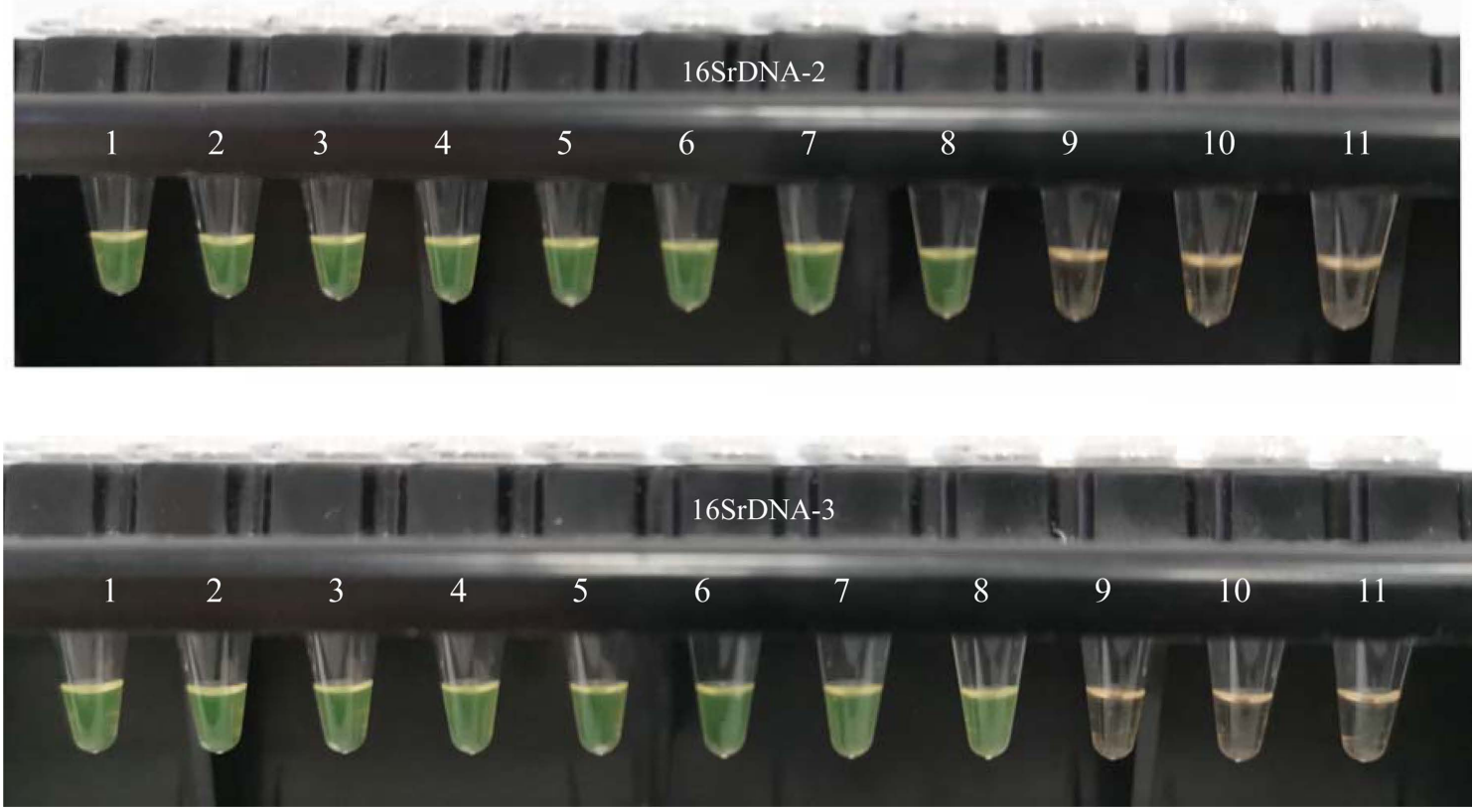

Fig. 6. Color change reactions of 16SrDNA-2 and 16SrDNA-3 loop-mediated isothermal amplification primers of Areca palm yellow leaf (AYL) phytoplasma. 1, $2 \mathrm{ng} / \mu \mathrm{l} ; 2,200 \mathrm{pg} / \mu \mathrm{l} ; 3,20 \mathrm{pg} / \mu \mathrm{l} ; 4,2 \mathrm{pg} / \mu \mathrm{l} ; 5,200 \mathrm{fg} / \mu \mathrm{l} ; 6,20 \mathrm{fg} / \mu \mathrm{l} ; 7,2 \mathrm{fg} / \mu \mathrm{l} ; 8,200 \mathrm{ag} / \mu \mathrm{l} ; 9,20 \mathrm{ag} / \mu \mathrm{l} ; 10$, $2 \mathrm{ag} / \mu \mathrm{l} ; 11$, deionized water. 


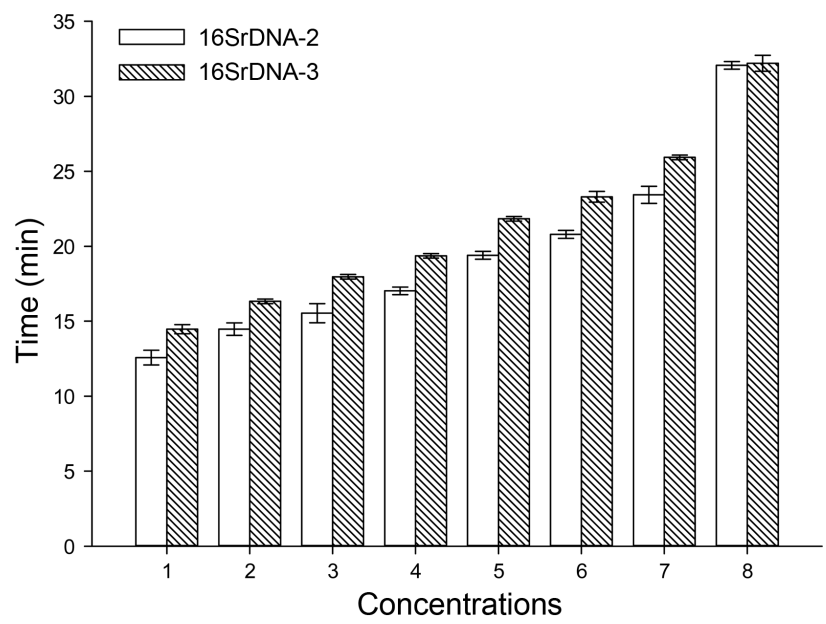

Fig. 7. Statistical analysis of the real-time amplification curve of 16SrDNA-2 and 16SrDNA-3 loop-mediated isothermal amplification primers. The arabic numerals $1-8$ in X axe represent $2 \mathrm{ng} /$ $\mu \mathrm{l}, 200 \mathrm{pg} / \mu \mathrm{l}, 20 \mathrm{pg} / \mu \mathrm{l}, 2 \mathrm{pg} / \mu \mathrm{l}, 200 \mathrm{fg} / \mu \mathrm{l}, 20 \mathrm{fg} / \mu \mathrm{l}, 2 \mathrm{fg} / \mu \mathrm{l}$, and $200 \mathrm{ag} / \mu \mathrm{l}$. *Significant difference with $P<0.05$.

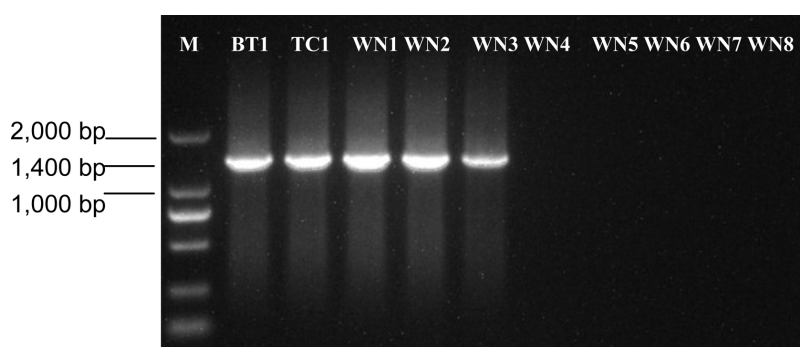

Fig. 8. PCR detection of Areca palm yellow leaf (AYL) disease and healthy samples from different countries of Hainan province in China. BT1, AYL disease sample from Baoting, Hainan; TC1, AYL disease sample from Tunchang, Hainan; WN1-WN3, AYL disease samples from Wanning, Hainan; WN4-WN8, healthy Areca palm samples from Wanning, Hainan; M, 2,000-bp molecular marker, with band sizes of 2,000, 1,000, 750, 500, 250, and $100 \mathrm{bp}$ from top to bottom; phytoplasma is $1,400 \mathrm{bp}$.

test samples with AYL disease from Baoting, Tunchang, and Wanning counties and not detected in the healthy Areca palm samples from Wanning county (Fig. 8). For the 16SrDNA-2 and 16SrDNA-3 LAMP detection system efficient for the 16SrI group AYL phytoplasma, an "S"-shaped curve was obtained for AYL disease samples from Baoting, Tunchang, and Wanning areas and the reaction appeared as emerald green after adding chromogenic solution before the reaction within $60 \mathrm{~min}$. No "S"-shaped curve appeared in non-diseased samples and the reaction did not turn to emerald green after adding chromogenic solution before the reaction, as shown in Figs. 9-11. Therefore, two sets of LAMP detection primers, 16SrDNA-2 and 16SrDNA-3,

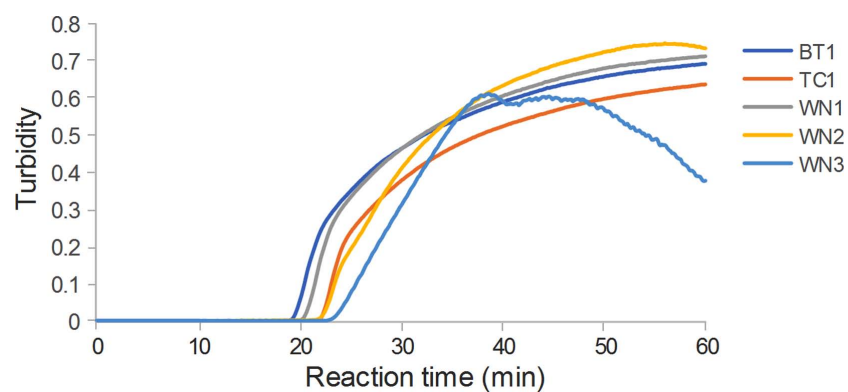

Fig. 9. Real-time amplification curve of 16SrDNA-2 loopmediated isothermal amplification primers of Areca palm yellow leaf (AYL) phytoplasma. BT1, AYL disease sample from Baoting, Hainan; TC1, AYL disease sample from Tunchang, Hainan; WN1-WN3, AYL disease samples from Wanning, Hainan.

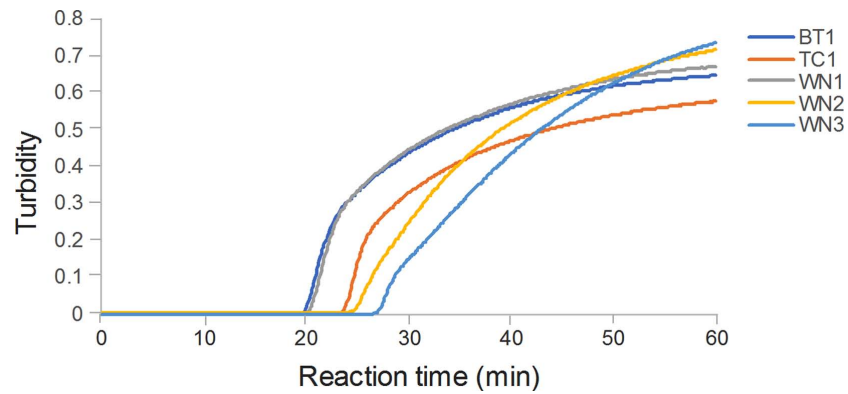

Fig. 10. Real-time amplification curve of 16SrDNA-3 loop-mediated isothermal amplification primers of Areca palm yellow leaf (AYL) phytoplasma. BT1, sample of AYL disease from Baoting, Hainan; TC1, sample of AYL disease from Tunchang, Hainan; WN1-WN3, samples of AYL disease from Wanning, Hainan.

showed good stability and comparatively high detection efficiency based on the 16S rRNA gene sequence.

\section{Discussion}

Phytoplasma disease is a systemic infection disease mainly transmitted by natural vectors, dodder, seedlings, and grafting performed by humans. The most common and fundamental method for preventing epidemics of this disease is to eliminate natural and human-facilitated spread of the pathogen from the source (Dickinson and Hodgetts, 2013). Therefore, establishing a rapid, efficient, and convenient method for detecting phytoplasma is very important in phytoplasma disease research and for disease monitoring, seedling quarantine, and comprehensive disease control. LAMP technology is an in vitro isothermal method for amplifying specific nucleic acid fragments and was developed by Notomi et al. (2000). Compared to detection by conventional nucleic acid amplification techniques, nested 

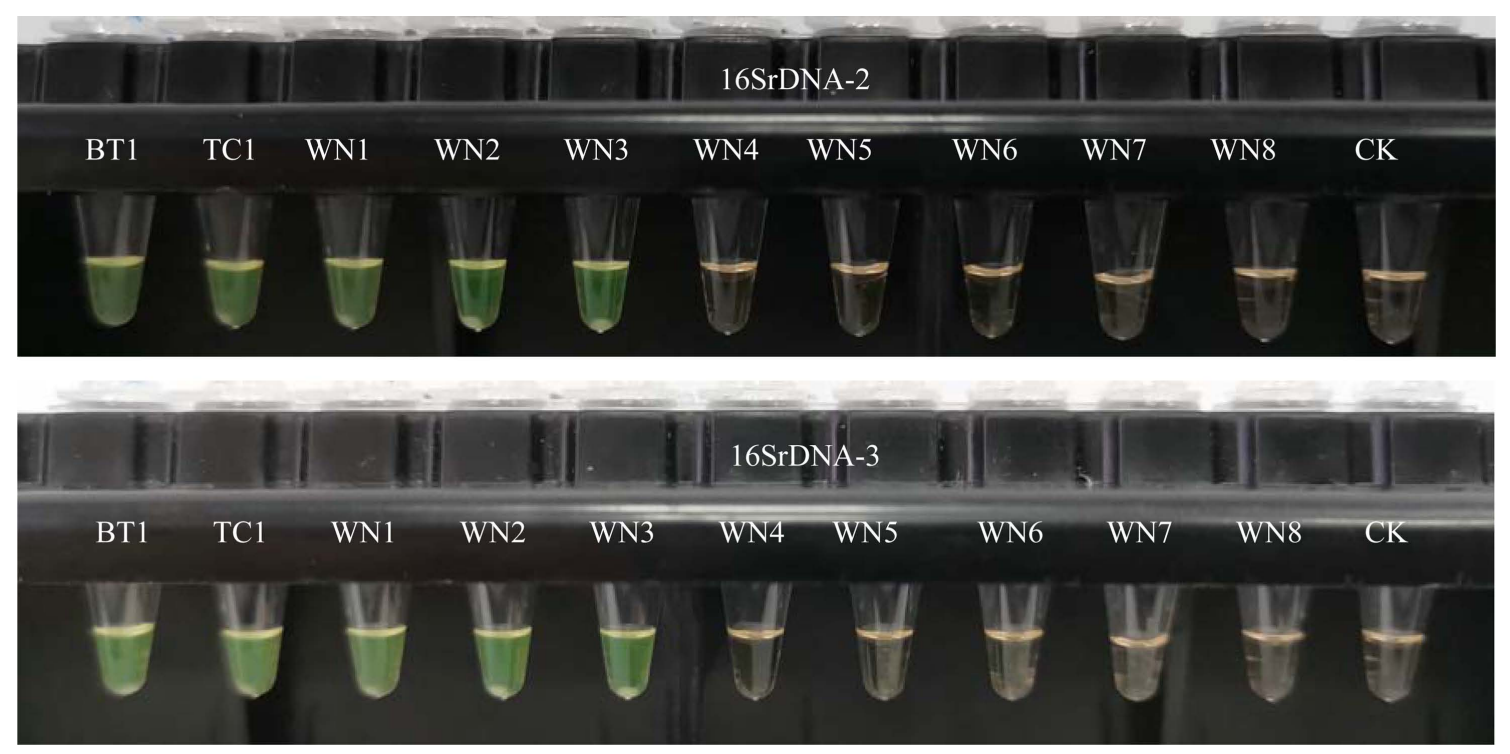

Fig. 11. Color change reactions of 16SrDNA-2 and 16SrDNA-3 loop-mediated isothermal amplification (LAMP) primers of AYL phytoplasma. BT1, AYL disease sample from Baoting, Hainan; TC1, AYL disease sample from Tunchang, Hainan; WN1-WN3, AYL disease samples from Wanning, Hainan; WN4-WN8, healthy samples of Areca palm from Wanning, Hainan; CK represents deionized water.

PCR and qPCR, LAMP technology is simpler and does not depend on costly thermal cycling instruments, has a shorter detection time, and is rapid, simple, and useful in the field (Nagamine et al., 2002; Notomi et al., 2000). In this study, two sets of LAMP primers, 16SrDNA-2 and 16SrDNA-3, were designed based on six regions of 16SrDNA, the target gene of AYL phytoplasma in Hainan province in China. During LAMP isothermal amplification, a dumbbell-like structure was formed via the function of strand replacement DNA polymerase. Constant temperature amplification of nucleic acids was achieved by using the dumbbelllike structure as a replication unit. In the reaction system, manganese ion combines with and quenches calcein. When large amounts of DNA are synthesized, pyrophosphate ion, the amplification by-product separated from dNTP in the reaction system, can combine with manganese ion and release manganese ion from calcein, resulting in calcein fluorescence. Additionally, the combination of $\mathrm{Mg}^{2+}$ and calcein in the reaction system further enhanced the fluorescence of calcein. Therefore, the results of LAMP can be visualized using calcein as an indicator; agarose gel electrophoresis is not required, resulting in rapid and highthroughput detection of the amplification results.

For phytoplasma that cannot be cultured in vitro from the host plants, LAMP primers are required not to amplify the homologous genes of the host plants. A key issue in LAMP detection technology is the selection of target genes and primer combinations. The target gene should contain a sequence that is highly conserved within strains and with high variation between strains. At present, the target genes of phytoplasma used in LAMP detection mainly include housekeeping genes such as 16S rRNA, tuf, and groEL (Obura et al., 2011; Sugawara et al., 2012; Wang et al., 2017). LAMP detection is mainly aimed at identifying the presence of phytoplasma diseases such as aster yellow witches'-broom, coconut lethal yellowing, 16SrXI group AYL, jujube witches'-broom and paulownia witches'broom (Nair et al., 2016; Obura et al., 2011; Sugawara et al., 2012; Wang et al., 2017). Wang et al. (2017) established an efficient LAMP technology for detecting 16SrI group phytoplasma disease based on tuf as the target gene; this method can detect phytoplasma such as paulownia witches'-broom phytoplasma belonging to the 16SrI-D subgroup and mulberry dwarf phytoplasma belonging to the 16SrI-B subgroup. Nair et al. (2016) constructed a LAMP detection system based on 16S rDNA for AYL phytoplasma belonging to the $16 \mathrm{SrXI}$ group in India. However, the sensitivity, and stability of the system varied widely based on the different target genes used in different groups or subgroups of host plants (Nair et al., 2016; Obura et al., 2011; Sugawara et al., 2012; Wang et al., 2017).

Two sets of LAMP primers were developed to efficiently detect 16SrI group AYL phytoplasma in Hainan province in China. These primers showed good detection sensitivity and stability for the target gene of AYL phytoplasma in samples with Areca palm yellow disease from Baoting, 
Tunchang, and Wanning counties in Hainan province, China. The sensitivity of the LAMP detection system depends on the target sequences, primers, detection methods, and group or subgroup of phytoplasma. Obura et al. (2011) reported that the sensitivity of detection for LAMP was 100-fold higher than that for nested PCR using the turbidimetric method and ethidium bromide staining agarose electrophoresis. Sugawara et al. (2012) found that the detection sensitivity varied for different LAMP primers and was 10-fold and 100-fold higher than that of conventional PCR. The sensitivities of LAMP for some phytoplasma strains in the 16SrI group based on the tuf gene and some phytoplasma strains in the $16 \mathrm{SrV}$ group were 8 - and 128 fold times higher than that of conventional PCR (Wang et al., 2017). The content of phytoplasma in AYL disease is relatively low and unevenly distributed within the phloem tissue of the palm; thus, it must be detected by nested PCR (Che et al., 2010). The two sets of LAMP primers constructed based on the 16S rRNA target gene were efficient and stable in detecting $16 \mathrm{SrI}$ group AYL phytoplasma in this study. The sensitivity of the two sets of primers in the LAMP detection system reached up to $200 \mathrm{ag} / \mu \mathrm{l}$, namely approximately 53 copies/ $\mu$ l of the target gene.

The nut produced by the Areca palm is an important resource used as traditional Chinese medicine in China. It is a perennial evergreen tree in the Palmaceae family and grows in China, India, Sri Lanka, Thailand, Vietnam, Myanmar, and Malaysia. Areca palm yellow disease has only been reported in China, India, and Sri Lanka (Che et al., 2010; Ramaswamy et al., 2013; Silva et al., 2015). The 16SrI-B subgroup and $16 \mathrm{SrXI}$ group AYL phytoplasma have been found in India (Muddumadiah et al., 2014; Ramaswamy et al., 2013), 16SrXV group AYL phytoplasma in Sri Lanka (Silva et al., 2015), and 16SrI-B and 16SrI-G subgroup in China (Che et al., 2010; Zhou et al, 2010). The phytoplasma content is relatively low and the latent period of the pathogen is comparatively long, which has a serious impact on pathogen detection and identification and epidemic monitoring, control, and management of AYL disease. In this study, two sets of LAMP primers were designed based on AYL phytoplasma belonging to the 16SrI-B subgroup in Hainan province, China; these efficient primers showed stability and high sensitivity. The detection limit of the two sets of LAMP primers was $200 \mathrm{ag} / \mu \mathrm{l}$. Based on the 16S rRNA gene sequence, two rapid, efficient, and simple LAMP systems for detecting AYL phytoplasma were established. These methods can be used in the early detection and field diagnosis of areca yellow disease, detection of areca seedlings with phytoplasma, and selection of resistant Areca palm varieties. These results provide a technical and theoretical basis for detecting and identifying AYL phytoplasma belonging to the 16SrI-B subgroup in Hainan province, China, as well as for efficient quarantine and control of AYL disease.

\section{Acknowledgments}

This research was supported by the Hainan Major Research Project for Science and Technology, China (zdkj201817).

\section{References}

Che, H. and Luo, D. 2011. A method for the detection of phytoplasma of Areca palm yellow leaf disease and its special kit. China Patent No. ZL200910077044.3.

Che, H., Wu, C., Fu, R., Wen, Y. and Luo, D. 2010. Molecular identification of pathogens from arecanut yellow leaf disease in Hainan. Chinese J. Trop. Crops 31:83-87 (in Chinese).

Deng, S. and Hiruki, C. 1991. Amplification of 16S rRNA genes from culturable and nonculturable Mollicutes. J. Microbiol. Methods 14:53-61.

Dickinson, M. and Hodgetts, J. 2013. Phytoplasma: methods and protocols. Humana Press, Totowa, NJ, USA. 421 pp.

Doi, Y., Teranaka, M., Yora, K. and Asuyama, H. 1967. Mycoplasma or PLT group-like microorganisms found in the phloem elements of plants infected with mulberry dwarf, potato witches' broom, aster yellows or paulownia witches' broom. Jpn. J. Phytopathol. 33:259-266 (in Japanese).

Lee, I. M., Hammond, R. W., Davis, R. E. and Gundersen, D. E. 1993. Universal amplification and analysis of pathogen $16 \mathrm{~S}$ rDNA for classification and identification of mycoplasmalike organisms. Phytopathology 83:834-842.

Muddumadiah, C., Madhupriya, Kumar, S., Manimekalai, R. and Rao, G. P. 2014. Detection and characterization of 16SrI-B phytoplasmas associated with yellow leaf disease of arecanut palm in India. Phytopathogenic Mollicutes 4:77-82.

Nagamine, K., Hase, T. and Notomi, T. 2002. Accelerated reaction by loop-mediated isothermal amplification using loop primers. Mol. Cell. Probes 16:223-229.

Nair, S., Manimekalai, R., Ganga Raj, P. and Hegde, V. 2016. Loop mediated isothermal amplification (LAMP) assay for detection of coconut root wilt disease and arecanut yellow leaf disease phytoplasma. World J. Microbiol. Biotechnol. 32:108.

Nair, S., Roshna, O. M., Soumya, V. P., Hegde, V., Manimekalai, R. and Thomas, G. V. 2014. Real-time PCR technique for detection of arecanut yellow leaf disease phytoplasma. Australasian Plant Pathol. 43:527-529.

Notomi, T., Okayama, H., Masubuchi, H., Yonekawa, T., Watanabe, K., Amino, N. and Hase, T. 2000. Loop-mediated isothermal amplification of DNA. Nucleic Acids Res. 28:e63.

Obura, E., Masiga, D., Wachira, F., Gurja, B. and Khan, Z. R. 2011. Detection of phytoplasma by loop-mediated isother- 
mal amplification of DNA (LAMP). J. Microbiol. Methods 84:312-316.

Ramaswamy, M., Nair, S., Soumya, V. P. and Thomas, G. V. 2013. Phylogenetic analysis identifies a 'Candidatus Phytoplasma oryzae'-related strain associated with yellow leaf disease of areca palm (Areca catechu L.) in India. Int. J. Syst. Evol. Microbiol. 63:1376-1382.

Schneider, B., Seemueller, E., Smart, C. D. and Kirkpatrick, B. C. 1995. Phylogenetic classification of plant pathogenic mycoplasma-like organisms or phytoplasmas. In: Molecular and diagnostic procedures in mycoplasmology, eds. by S. Razin and J. G. Tully, pp. 369-380. Academic Press, San Diego, CA, USA.

Silva, C. K., Damayanthi, M., de Silva, R., Dickinson, M., de Silva, N. and Udagama, P. 2015. Molecular and scanning electron microscopic proof of phytoplasma associated with areca palm yellow leaf disease in Sri Lanka. Plant Dis. 99:1641.

Sugawara, K., Himeno, M., Keima, T., Kitazawa, Y., Maejima, K., Oshima, K. and Namba, S. 2012. Rapid and reliable detection of phytoplasma by loop-mediated isothermal amplification targeting a housekeeping gene. J. Gen. Plant Pathol. 78:389397.

Wang, S., Wang, S., Lin, C., Yu, S., Wang, L., Piao, C., Guo, M. and Tian, G. 2017. Loop-mediated isothermal amplification assay for detection of five phytoplasmas belonging to $16 \mathrm{SrI}$ group based on target tuf gene. Sci. Silvae Sin. 53:54-63 (in Chinese).

Yu, S., Li, Y., Ren, Z., Song, C., Lin, C., Piao, C. and Tian, G. 2017. Multilocus sequence analysis for revealing finer genetic variation and phylogenetic interrelatedness of phytoplasma strains in 16SrI group in China. Sci. Silvae Sin. 53:105-118 (in Chinese).

Zhou, Y., Gan, B., Zhang, Z., Sui, C., Wei, J., Yang, Y. and Yang, X. 2010. Detection of the phytoplasmas associated with yellow leaf disease of Areca catechu L. in Hainan province of China by nested PCR. Chinese Agric. Sci. Bull. 26:381-384 (in Chinese). 